\title{
Use and risks of surgical mesh for pelvic organ prolapse surgery in women in New York state: population based cohort study
}

In this Research paper by Bilal Chughtai and colleagues (BMJ 2015;350:h2821,h2685 doi:10.1136/bmj.h2685) there are some text errors. In the third paragraph of the Introduction, the third sentence should read: “A 2013 Cochrane review did not report increased failure occurrence with mesh repair, but it was limited by overall size (less than 500 mesh patients [not " $<500$ patients"]) and lacked data for safety and patient morbidity."
In the third paragraph of the section "Comparison with previous studies," the second and third sentences should refer to "mesh erosion" rather than "mesh exposure," to convey the instances of exposed mesh.

Cite this as: BMJ 2015;350:h3060

๑ BMJ Publishing Group Ltd 2015 